Enferm Bras 2019;18(6):775-83

https://doi.org/10.33233/eb.v18i6.3255

\title{
ARTIGO ORIGINAL \\ Punção de veias periféricas em adultos hospitalizados: método misto sequencial aninhado
}

Cristina Arreguy-Sena, D.Sc. ${ }^{*}$, Laércio Deleon de Melo, M.Sc. **, Luciene Muniz Braga, D.Sc. ${ }^{* *}$, Paula Krempser, D.Sc. ${ }^{* \star *}$, Romanda da Costa Pereira Barboza Lemos, M.Sc. ${ }^{\star \star \star \star *}$, Daniela de Paula Lopes, M.Sc. ${ }^{* * * *}$

${ }^{\star}$ Enfermeira, Professora Titular, Universidade Federal de Juiz de Fora (UFJF), Juiz de Fora/MG, ${ }^{*}$ Enfermeiro, Mestre em Enfermagem pela Universidade Federal de Juiz de Fora (UFJF), ${ }^{* * *}$ Enfermeira, Professora Adjunta, Universidade Federal de Viçosa (UFV), Viçosa/MG, ${ }^{* * * * E n f e r m e i r a, ~ P r o f e s s o r a ~ A d j u n t a, ~ U n i v e r s i d a d e ~ F e d e r a l ~ d e ~ J u i z ~ d e ~ F o r a ~(U F J F), ~}$

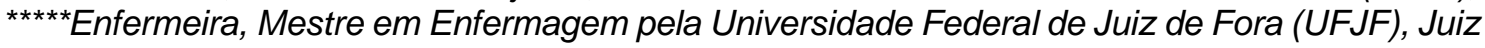
de Fora/MG

Recebido em 27 de setembro de 2019; aceito em 23 de dezembro de 2019.

Correspondência: Laércio Deleon de Melo, Rua Doutor Dirceu de Andrade, 201/305, 36025330 Juiz de Fora MG

Laércio Deleon de Melo: laerciodl28@hotmail.com

Cristina Arreguy-Sena: cristina.arreguy@gmail.com

Luciene Muniz Braga: luciene.muniz@ufv.br

Paula Krempser: paula@krempser.com.br

Romanda da Costa Pereira Barboza Lemos: romanda.barboza@gmail.com

Daniela de Paula Lopes: danilops737@gmail.com

\section{Resumo}

Introdução: A punção de vasos periféricos é um procedimento invasivo realizado por profissionais da saúde com interpretações e significados distintos entre as pessoas. Objetivo: Identificar os conteúdos, a estrutura e a origem das representações sociais sobre punção venosa periférica por pessoas internadas e analisar seus sentimentos e comportamentos autorrelatados durante as etapas desse procedimento. Métodos: Estudo misto tipo sequencial aninhado (Teoria das Representações Sociais e seccional) realizado em hospital de ensino filantrópico que presta $100 \%$ dos serviços contratualizados ao Sistema Único de Saúde. Participaram 150 pessoas internadas com veias periféricas puncionadas. Realizou-se entrevista individual usando técnica de evocação livre de palavras e coleta de sentimentos e comportamentos durante o processo de punção venosa a partir de questionário próprio. Foram feitas análises: prototípica e estatística descritiva. Atenderam-se os aspectos ético-legais. Resultados: No possível núcleo central constam conteúdos comportamentais (dor-sofrimento, medo e nervosismo) e objetivais (soromedicamento) em oposição à área de contraste (quieto-controle). Houve predominância de sentimentos e comportamentos de caráter negativo. Conclusão: Os conteúdos representacionais versaram sobre respostas humanas valorativas de caráter negativo, retratando dificuldades dos participantes em lidar com a punção de vasos, o que remete à necessidade de a equipe de enfermagem identificar e monitorizar terapeuticamente tais respostas.

Palavras-chave: cuidados de enfermagem, punções, cateterismo periférico, hospitalização, psicologia social.

\footnotetext{
Abstract

Peripheral vein puncture in hospitalized adults: nested sequential mixed method

Introduction: Peripheral vessel puncture is an invasive procedure performed by health professionals with different interpretations and meanings among people. Objective: To identify the contents, structure and origin of social representations about peripheral venipuncture by hospitalized people and to analyze their self-reported feelings and behaviors during the stages of this procedure. Methods: Sequential mixed study (Theory of Social Representations and crosssectional) conducted in a philanthropic teaching hospital that provides $100 \%$ of the services contracted to the Unified Health System. Hundred fifty people admitted with punctured peripheral
} 
veins. Individual interviews were performed using free word evocation technique and collection of feelings and behaviors during the venipuncture process through a proper questionnaire. Analyzes were performed: prototypic and descriptive statistics. The ethical-legal aspects were considered. Results: The possible central nucleus contains behavioral (pain-suffering, fear and nervousness) and objective (serum-drug) contents as opposed to the contrast area (quiet control). There was a predominance of negative feelings and behaviors. Conclusion: The representational contents dealt with negative evaluative human responses, portraying participants' difficulties in dealing with vessel puncture, which refers to the need for the nursing team to identify and therapeutically monitor such responses.

Key-words: nursing care, punctures, catheterization, peripheral, hospitalization, social psychology.

\section{Resumen}

Punción de vena periférica en adultos hospitalizados: método mixto secuencial anidado Introducción: La punción de los vasos periféricos es un procedimiento invasivo realizado por profesionales de la salud con diferentes interpretaciones y significados entre las personas. Objetivo: Identificar los contenidos, la estructura y el origen de las representaciones sociales sobre la venopunción periférica por parte de personas hospitalizadas y analizar sus sentimientos y comportamientos autoinformados durante las etapas de este procedimiento. Métodos: Estudio mixto secuencial anidado (Teoría de las representaciones sociales y seccional) realizado en un hospital de enseñanza filantrópico que proporciona el 100\% de los servicios contratados al Sistema Único de Salud. Los participantes fueron 150 pacientes hospitalizados con venas periféricas perforadas. Las entrevistas individuales se realizaron utilizando la técnica de evocación de palabras libres y la recopilación de sentimientos y comportamientos durante el proceso de venopunción a través de un cuestionario adecuado. Se realizaron análisis: estadísticas prototípicas y descriptivas. Se consideraron los aspectos ético-legales. Resultados: El posible núcleo central contiene contenido conductual (sufrimiento, dolor y nerviosismo) y objetivo (suero de drogas) en comparación con el área de contraste (control silencioso). Hubo un predominio de sentimientos y comportamientos negativos. Conclusión: El contenido representacional se ocupó de las respuestas humanas negativas evaluativas, retratando las dificultades de los participantes para lidiar con la punción de los vasos, lo que se refiere a la necesidad de que el equipo de enfermería identifique y monitoree terapéuticamente dichas respuestas.

Palabras-clave: atención de enfermería, punciones, cateterismo periférico, hospitalización, psicología social.

Introdução

A Punção de Vasos Periféricos (PVP) é um procedimento invasivo, realizado por profissionais da saúde, com interpretações e significados distintos entre as pessoas [1,2]. Esta atividade é realizada para fins farmacológicos, hemoterápicos ou diagnósticos, o que, para uma pessoa leiga, pode propiciar o acesso de memórias recentes ou remotas e ocasionar manifestações de conteúdos coletivos que se exprimem através de sentimentos, comportamentos, atitudes, valores, crenças, informações, imagens e objetos [2-4].

Nesta investigação, a PVP está sendo concebida como um procedimento técnico, realizado por uma equipe de enfermagem treinada, cuja técnica consiste em introduzir, posicionar, manter e monitorar um Cateter Intravascular (CIV) no interior de uma veia conforme indicação clínica de seu uso, assegurando sua terapêutica e qualificando a assistência prestada $[1,2]$.

As finalidades do CIV incluem: possibilitar reposição volêmica, assegurar níveis plasmáticos de princípios farmacológicos, favorecer procedimentos de prova funcional e diagnóstica, viabilizar tratamento hemoterápico e assegurar uma via rápida para intervenção farmacológica em caso de instabilidade hemodinâmica [1].

Para a instalação de um CIV, o enfermeiro necessita de habilidades como a tomada de decisão alicerçada em posicionamentos técnicos, gerenciais, terapêuticos e operacionais para a escolha do material e do local da instalação do cateter, para sua remoção e nos cuidados pósremoção no período compreendido entre sua instalação até a retirada e posterior reconstituição da ponte epitelial no sítio de inserção do cateter, a ponto de garantir a segurança daqueles que têm suas veias puncionadas para fins diagnósticos ou terapêuticos [5]. 
A partir desta compreensão, optou-se pelo uso da abordagem estrutural da Teoria da Representação Social (TRS), visando à captação de conteúdo, estrutura e origens das construções simbólicas da PVP como um objeto socialmente compartilhado [3]. Considerou-se o contexto em que é realizada a PVP durante a hospitalização das pessoas, somado às experiências prévias durante o acompanhamento de familiares, pelo conhecimento socialmente compartilhado no contato com terceiros, pessoas leigas que passaram pelo procedimento ou profissionais $[3,4]$.

Ao considerar a diversidade de possíveis vivências por parte das pessoas que têm suas veias puncionadas, surgiram as seguintes indagações: Quais as Representações Sociais (RS) que pessoas internadas possuem a respeito da PVP? Será que essas RS significam formas de enfrentamento diante do procedimento? Elas podem se traduzir em respostas humanas a ponto de nortear o planejamento do cuidado de enfermagem? Como os sentimentos e comportamentos das pessoas que vivenciam a PVP podem influenciar o seu tratamento e a realização dos cuidados de enfermagem?

Diante do exposto, a presente investigação se justifica por ser a PVP uma prática corriqueira entre as atividades laborais do enfermeiro e de sua equipe e possuir importância para a terapia venosa e o pronto-atendimento em casos de instabilidade clínica das pessoas internadas. A PVP gera sentimentos, percepções e comportamentos diversificados nos grupos sociais.

Para responder a tais indagações, buscou-se identificar no contexto de prática clínica da enfermagem as percepções dos usuários sobre a PVP no intuito de captar como eles se sentem, comportam e representam esse procedimento. Sendo assim, objetivou-se identificar os conteúdos, a estrutura e a origem das representações sociais sobre PVP por pessoas internadas e analisar seus sentimentos e comportamentos autorrelatados durante as etapas desse procedimento.

\section{Material e métodos}

Utilizou-se método misto de investigação, tipo sequencial aninhado com etapas, a saber: qualitativa - abordagem estrutural da TRS $[6,7]$ e quantitativa - pesquisa seccional do tipo exploratório e descritivo.

Foram cenários desta pesquisa os setores de internação cirúrgica (geral, plástica e ortopedia), clínica médica e maternidade de um Hospital de Ensino Filantrópico que disponibiliza $100 \%$ de seus leitos de forma contratualizada ao Sistema Único de Saúde (SUS) numa cidade de Minas Gerais, Brasil.

Foram critérios de inclusão: 1) Pessoas internadas em setores clínicos, cirúrgicos e maternidade; 2) Idade $\geq 18$ anos; 3) Pessoas cujas veias foram puncionadas na instituição; 4) Pessoas com nível de cognição compatível com a abordagem investigativa realizada. Foram excluídas: 1) Pessoas por perda de seguimento decorrente do desejo expresso em interromper a participação e 2) Pessoas em Pós-operatório Imediato (POI), com dispneia ou instabilidade hemodinâmica.

Amostra de seleção completa sequencial (tamanho amostral determinado por recorte temporal de três meses). Cabe mencionar que o critério de redução de vieses associado ao tamanho amostral diminui à medida que se intensificam as chances de se obter resultados condizentes com a realidade a partir de cem observações [8].

O recrutamento se deu por convite individual à beira do leito, tendo sido abordadas 191 pessoas, houve 41 exclusões - POI: 28; dispneia e confusão mental: 10; desejo de interromper a participação: 3, perfazendo 150 participantes inclusos após esclarecimento dos objetivos da pesquisa pelos pesquisadores e coleta de assinatura do Termo de Consentimento Livre e Esclarecido (TCLE).

O instrumento de coleta de dados foi estruturado em cinco etapas, a saber: 1) Caracterização sociodemográfica; 2) Caracterização do PVP (localização, finalidade da punção, local puncionado, ocasião, número de tentativas/repunções e experiências prévias); 3) Técnica de evocação a partir do termo indutor "pegar veia"; 4) Sentimentos e comportamentos autorrelatados em cada etapa (antes da instalação do CIV e durante, bem como na manutenção, remoção e pós-remoção do CIV).

Os dados foram coletados em janeiro e fevereiro de 2015 por dois dos pesquisadores previamente treinados para as abordagens e enfoques pretendidos na investigação. Os dados de caracterização dos participantes e do estudo seccional foram consolidados e tratados no 
software Statistical Package for the Social Sciences (SPSS) versão 24, por análise descritiva, utilizando dados de tendência central e de dispersão.

Com a técnica de evocação livre de palavras, foram registradas as cinco primeiras palavras ou expressões que viessem à mente dos participantes para o termo indutor "pegar veia". A análise das evocações atendeu aos critérios lexicais e semânticos [9]. Foi construído o dicionário mediante avaliação do corpus original com auxílio do software Ensemble de Programmes Permettant L'analyse des Evocations (EVOC) versão 2003 e elaboração do quadro de quatro casas. Adotou-se a análise prototípica (frequência mínima de 18 e a intermediária $\geq$ 26 e a Ordem Média de Evocações OME $\geq 2,5$ ) a partir de um corpus de 612 evocações emitidas, sendo destas 31 palavras distintas.

Foram atendidos todos os requisitos éticos e legais de pesquisa envolvendo seres humanos, houve aprovação em Comitê de Ética em Pesquisa (parecer consubstanciado no 522.853 em 06/02/2014).

\section{Resultados}

Participaram 150 pessoas, sendo predominantemente: mulheres (75,7\%); com ensino fundamental completo $(53,4 \%)$; cor da pele autodeclarada parda $(39,2 \%)$; com companheiro $(48,7 \%)$ e com filhos $(80,4 \%)$, sendo de um a três filhos (54\%). A maioria exercia as seguintes atividades profissionais: técnicas $(31,9 \%)$, no comércio $(10,1 \%)$, domésticas $(10,1 \%)$, serviços gerais $(9,5 \%)$ e do lar $(8,8 \%)$.

O perfil de internação foi: $74,3 \%$ tinham vivenciado internações anteriores, dessas $58,8 \%$ já haviam sido internadas uma ou duas vezes. Quanto ao motivo da internação atual, 39,9\% das pessoas o fizeram para realização de parto e 68,7\% por motivos clínicos (cardiológicos, neurológicos, pneumológicos ou por distúrbios gastrointestinais).

As veias foram puncionadas para fins de coleta de sangue (55,3\%), para viabilizar algum tratamento durante a internação hospitalar $(44,7 \%)$, tendo sido essas punções realizadas no: braço $(51,1 \%)$; antebraço $(24,1 \%)$ ou dorso da mão $(24,8 \%)$. Vivenciaram a experiência de apenas uma tentativa de punção $(73,6 \%)$ e duas ou mais tentativas $(26,4 \%)$. Houve necessidade de repunção em uma a duas ocasiões $(18,9 \%)$ ou três ou mais vezes $(25 \%)$ para assegurar que o tratamento fosse concluído. Entre os participantes, $85,1 \%$ já haviam presenciado a realização de uma PVP, sendo 70,6\% em pessoas desconhecidas.

Os tipos de manifestações de traumas vasculares autopercebidos pelos participantes em PVPs anteriores foram: sangramento $(51,4 \%)$, dor $(41,9 \%)$, hematoma $(37,8 \%)$, edema $(20,9 \%)$, endurecimento de trajeto $(19,6 \%)$, hiperemia $(15,5 \%)$, endurecimento no sítio de inserção do CIV $(13,5 \%)$ e presença de secreção purulenta $(2 \%)$.

Foram identificados os sentimentos e os comportamentos autorreferidos pelos participantes sobre cada etapa do processo de PVP (Gráfico 1). 


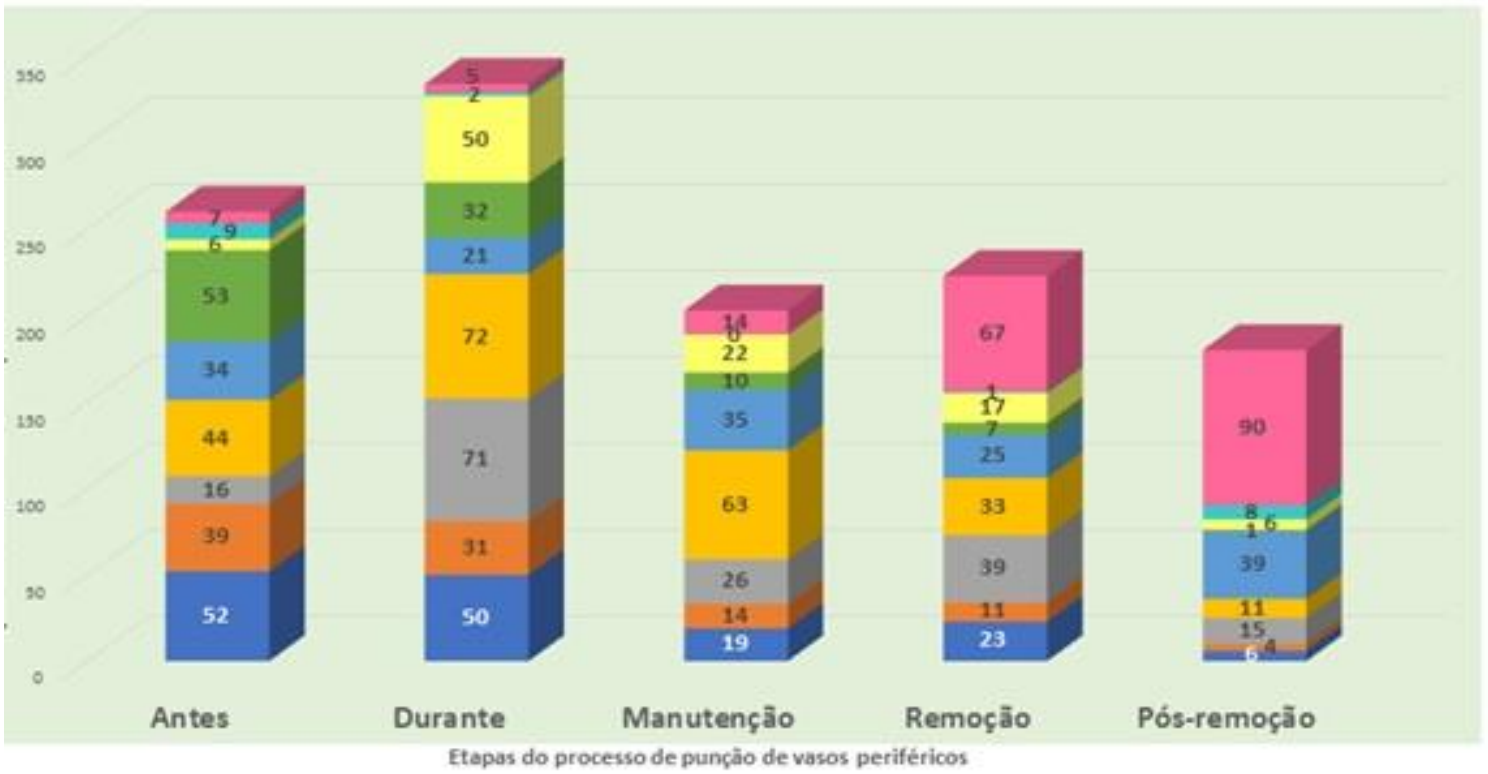

= Medo $=$ insegurança $\equiv$ Dor $=$ Desconforto $=$ Indiferença $=$ Ansiedade $\quad$ Ardéncia $=$ Nenhuma sensaçăo $\equiv$ Alivio

Fonte: Software Microsoft Excel 2019.

Gráfico 1 - Sentimentos e comportamentos autorreferidos pelas pessoas internadas $(n=150)$.

Os tipos de sentimentos e comportamentos predominantes nas etapas de punção foram: antes (ansiedade 53\%, medo 52\% e desconforto 44\%); durante (desconforto $72 \%$, dor $71 \%$ e medo e ardência ambos com 50\%); na manutenção (desconforto 63\%, indiferença 35\% e dor $26,5 \%$ ); na remoção (alívio $67 \%$, dor 39\% e desconforto 33\%) e na etapa pós-remoção (alívio $90 \%$, indiferença 39\% e dor em 15\%) conforme apresentado no Gráfico 1.

A seguir, consta o quadro de quatro casas com a alocação do cognemas evocados por 150 participantes para o termo indutor "pegar veia" (Figura 1).

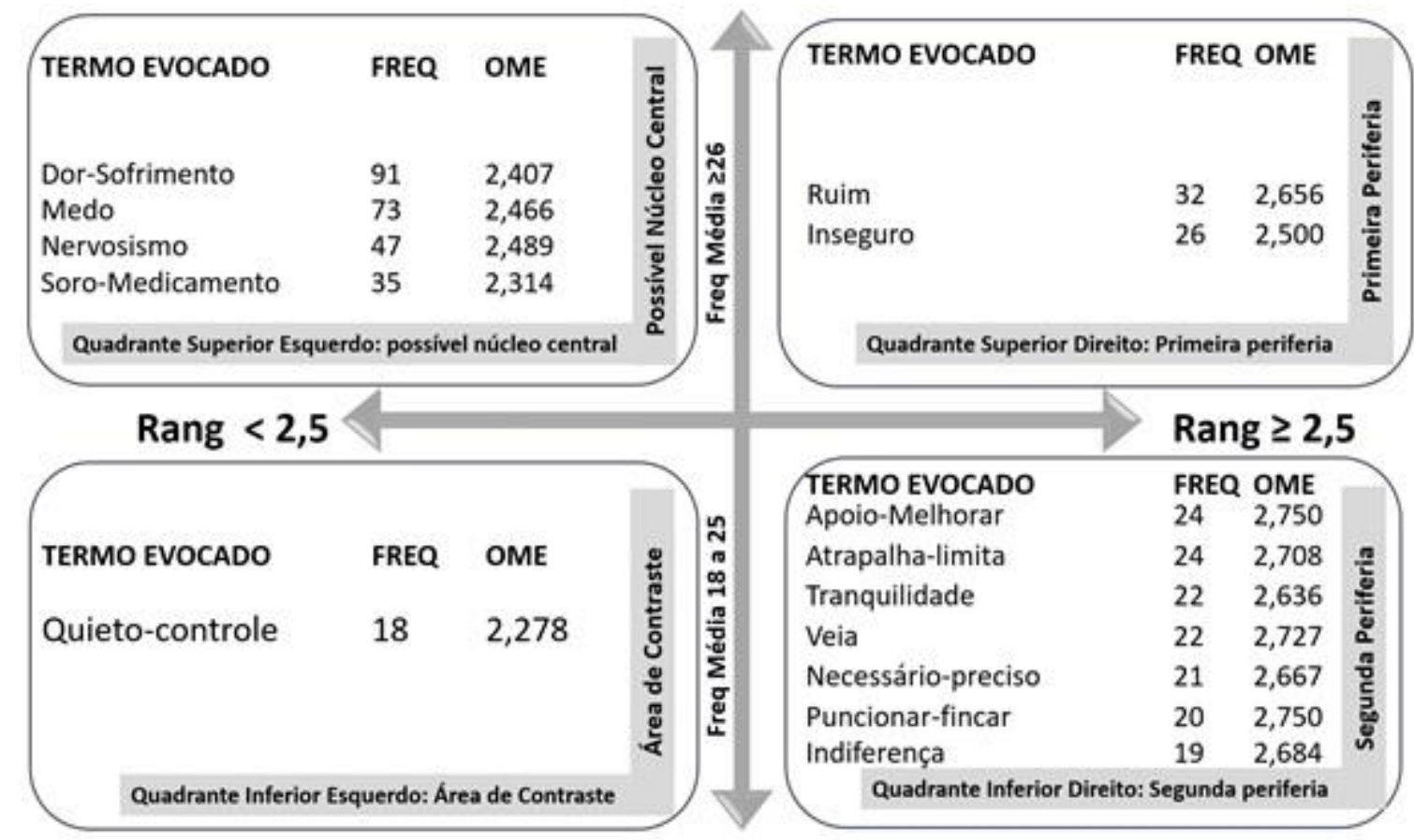

Fonte: Conteúdo extraído do SPSS versão 24.

Figura 1 - Quadro de quatro casas, análise estrutural das representações de pessoas internadas para o termo indutor "pegar veia" $(n=150)$. 
As RS referentes a "pegar veia" apresentaram o possível núcleo central ancorado em sentimentos negativos, que expressaram dor, sofrimento, medo e nervosismo, sendo objetivado pelo termo "soro-medicamento", que representa a finalidade do procedimento. Na área de contraste, emergiu a dimensão comportamental de submissão através da expressão "quietocontrole" e, nas periferias, elementos que reforçam o possível núcleo central.

\section{Discussão}

A análise comparativa dos dados censitários com os estimados para o ano de 2018 para o município em que os dados foram coletados apontou um crescimento de $8,5 \%$ da população, com predomínio do sexo feminino (272.223) quando comparado aos homens (244.024) [10]. O perfil dos participantes foi corroborado segundo gênero, idade e cor de pele declarada, sendo que houve mais hospitalização entre as mulheres com idade de 18 e 37 anos, o que se justifica pelo fato de o cenário de investigação possuir maternidade e ser referência para as gestantes da região.

Relataram que presenciaram a PVP em um desconhecido $70,6 \%$ dos participantes e isso pode ser explicado tendo em vista que a instituição possui enfermarias conjuntas com até seis leitos, de modo que se pode presenciar a realização PVP em pessoas internadas no ambiente terapêutico compartilhado.

Ao analisar o quadro de quatro casas, puderam-se identificar no possível núcleo central três situações: "dor-sofrimento", "medo-ansiedade" e "nervosismo". Tais cognemas retratam a dificuldade dos participantes em vivenciar a PVP objetivada pela expressão "soro-medicamento", sendo que essas três primeiras evocações retratam formas negativas e conflituosas associadas à percepção da PVP, enquanto que a expressão "soro-medicamento" se traduz, em linguagem popular, nas soluções e nos fármacos que são infundidos durante o período de internação hospitalar, como parte integrante da conduta terapêutica.

Outra sensação que a pessoa puncionada enfrenta é a dor. Esta poderá ser aguda ou crônica e constitui-se em experiências sensoriais e emocionais desagradáveis associadas à lesão tissular real ou em potencial $[11,12]$. Outros estudos apontam o trauma mais incidente decorrente da PVP, mas passível de prevenção /diminuição de sua ocorrência com boas práticas de enfermagem [13].

No caso da PVP, esse procedimento paradoxalmente poderá ser instituído para reduzir dores crônicas (tempo $>3$ meses) ou agudas. Embora o próprio procedimento, por romper a barreira da pele e tecidos, até a estabilização do CIV no interior do vaso, possa gerar algum tipo de experiência dolorosa controlável ou insuportável, a percepção é individual, apesar da padronização da realização da PVP [13-15].

Resultados do estudo secional corroboraram a existência da dor por meio da identificação de dois picos de incidência (ao ser introduzido ou removido o CIV) deduzidos dos relatos dos participantes, estando ausente antes da aplicação do CIV e decrescente nos momentos posteriores à introdução (antes: ausente; durante: 4\%; manutenção: 17,6\%; remoção do cateter: $26,4 \%$ e pós-remoção: $10,1 \%$ ).

A abordagem terapêutica da dor decorrente do processo de PVP envolve: 1) encorajamento para que a pessoa expresse sua experiência, descrevendo-a e identificando suas causas, duração e sensações; 2) compreensão de que a dor decorrente da instalação do CIV é transitória, o que pode auxiliar em seu enfrentamento; 3) necessidade de avaliação profissional para descartar lesões de nervos ou manifestações de trauma vascular em fase inicial; 4) explicação da finalidade da PVP, o que favorece sua aceitação e a adesão ao tratamento de modo a envolver a pessoa de forma colaborativa na conduta terapêutica e 5) distinção no processo de instalação do cateter entre ações profissionais que geram desconforto (garroteamento) e dor (introdução do CIV), o que operacionaliza o procedimento [15,16].

Outra possibilidade de minimização da dor é o uso de anestésicos locais, como a lidocaína via intradérmica, sendo recomendado o uso desses anestésicos antes das punções quando o CIV possuir calibre $\geq 17 G$ [16].

A expressão "medo-ansiedade" refere-se a uma resposta humana desencadeada mediante situações reais, potenciais ou imaginárias, consideradas ou percebidas como perigosas ou geradoras de ameaça física, emocional, psicológica ou social que se manifesta pela exacerbação simpática. As manifestações clínicas podem incluir: taquicardia, taquipneia, irritabilidade, inquietação, tensão emocional e sensação de perigo. Tais manifestações ocasionam comportamentos que demonstram desconforto, sendo facilmente reconhecidos por quem está próximo [14]. 
A ansiedade envolve um sentimento vago e incômodo de desconforto ou temor, acompanhado por uma resposta autônoma com sensação de apreensão, causada pela antecipação de perigo. O medo, por outro lado, é desencadeado por uma ameaça real ou potencial autopercebida por uma pessoa ou alguém [14].

Tais manifestações são mais evidentes e explícitas entre as crianças, visto que adultos preferem mostrar que têm o controle da situação de modo a utilizarem-se de "persona" que é projetada como estratégia de enfrentamento e ocultação de situações consideradas ameaçadoras [14,15].

Nos resultados do estudo secional, a existência de medo e ansiedade foi confirmada a partir da incidência de medo (antes: $35,1 \%$; durante: 33,8\%; manutenção: 12,8\%; remoção: 13,5\%; pós-remoção: 4,1\%) e ansiedade (antes: 35,8\%; durante: 21,6\%; manutenção: 6,8\%; remoção: $7 \%$; pós-remoção: $0,7 \%$ ). O nervosismo relatado durante o procedimento esteve presente no quadro de quatro casas e foi corroborado pelo estudo seccional (antes: $25 \%$; durante: 25,7\%; manutenção: 12,2\%; remoção: $11,5 \%$; pós-remoção: $2,7 \%$ ).

No cômputo geral, houve maior incidência de medo, ansiedade e nervosismo no período que antecede a operacionalização da introdução do CIV e durante, mantendo-se presente na manutenção e remoção do CIV, com redução significativa somente após a remoção do CIV. Seu enfrentamento requer o estabelecimento de uma relação terapêutica baseada na confiança e no respeito, a disponibilização de informações apropriadas e o auxílio à pessoa na identificação de formas de lidar com a situação e criar estratégias para reduzir o desconforto apresentado em cada etapa do processo de PVP [15].

As respostas humanas de valor negativo identificadas, do ponto de vista terapêutico, retratam a necessidade de o enfermeiro captar, compreender e encorajar as pessoas internadas a externarem suas representações, sentimentos e comportamentos de modo a caracterizar estratégias de enfrentamento para elas ao vivenciarem o processo de PVP segundo as perspectivas e singularidades do grupo social $[5,15]$.

Nesse sentido, a identificação das RS, sentimentos e comportamentos diante do processo de PVP deve ser o foco de atuação profissional, cabendo ao enfermeiro: explicar o procedimento numa linguagem de fácil compreensão e passo a passo à pessoa que terá uma veia puncionada; utilizar estratégias de empatia e interação interpessoal; auxiliar as pessoas a exprimirem suas emoções, sensações e ideias preconcebidas; estar atento à comunicação verbal e não verbal; inserir indagações quanto às possíveis sensações; estabelecer um vínculo de confiança com o usuário do serviço para que tenha suas incertezas reduzidas diante das atividades terapêuticas que vivenciará $[5,15]$.

A presença da expressão "quieto-controle" na área de contraste traduz um comportamento contrário aos conteúdos que integram o possível núcleo central, retratando um comportamento de submissão do grupo diante da PVP. Uma investigação australiana descreveu comportamentos e o engajamento de pessoas internadas influenciados por: 1) vínculos de poder tradicionais inerentes a relações e contextos de cuidado; 2) julgamento que os profissionais fazem de sua habilidade e autonomia das pessoas internadas para decidir em seu benefício e 3) normas e rotinas institucionais que circunscrevem as pessoas internadas a ponto de reduzirem seu envolvimento e opinião sobre as ações terapêuticas, gerando limitações de caráter pessoal, relacional e organizacional [17].

Os cognemas "ruim" e "inseguro", componentes da primeira periferia, representam sentimentos negativos e de insegurança do grupo social diante do procedimento de PVP. Na segunda periferia, foram retratadas quatro situações distintas que traduzem condições de dissenso para o grupo social, embora sejam formas individualizadas de perceber o processo de PVP, a saber: 1) "apoio-melhorar" e "necessário-preciso" demonstram um reconhecimento da necessidade do procedimento para a reabilitação de sua saúde; 2) "puncionar-fincar" remete à instalação do CIV - as recomendações para que o número de tentativas de punções não seja superior a duas, evitando trauma e estabelecendo parâmetros para tomada de decisões clínicas para outra forma de acessibilidade vascular [5]; 3) "atrapalha-limita" refere-se às limitações de movimentos e/ou atividades mediante a venóclise ou simplesmente pela presença do CIV salinizado, que ocasiona desconforto; 4) "veia" objetiva o processo de PVP por referir-se ao local em que se instalam os CIVs; as veias podem ser classificadas de acordo com o trajeto, mobilidade, visibilidade, palpação, calibre, localização, elasticidade e quanto à presença/ausência de solução de infusão contínua, e as indicadas à punção são retilíneas, fixas, facilmente palpáveis e visíveis [5] e 5) "indiferença" e "tranquilidade" retratam a presença de uma possível zona muda. 
A zona muda é concebida como espaços de compartilhamento de ideias de um determinado grupo que não são acessadas com facilidade por formas diretas como questionários e entrevistas, por se tratar de conteúdos que desvelam hábitos, estereótipos, formas de pensar e agir que podem ser alvo de preconceitos e/ou avaliação negativa por parte de quem ouve [8].

Evidenciou-se assim a necessidade de o enfermeiro fazer uma releitura sobre a implementação de estratégias terapêuticas capazes de contribuir para a segurança e o bemestar das pessoas internadas, quando se pensa em um cuidado de qualidade capaz de abarcar um procedimento técnico realizado como prática diária da equipe de enfermagem.

\section{Conclusão}

Foi possível compreender o processo de PVP na perspectiva de pessoas internadas, o qual apresentou conteúdos representacionais corroborados pelos sentimentos e comportamentos autorreferidos, que se expressaram predominantemente por dimensões valorativas e de caráter negativo, oriundos das experiências próprias e da convivência com outros pacientes internados.

Cabe destacar que a objetivação pelos cognemas "soro-medicamento" traduz uma das finalidades terapêuticas que justificam a realização do procedimento. Assim como os cognemas "medo, dor/desconforto e nervosismo" se referem a sentimentos e comportamentos expressos pelo grupo e que necessitam ser monitorados terapeuticamente.

A expressão evocada "quieto-controle" retrata o comportamento de um subgrupo de participantes que se posicionam de forma submissa diante da realização da PVP e demonstra falta de empoderamento da pessoa cuidada, sendo corroborada pela oscilação de sentimentos e comportamentos autorreferidos segundo a etapa do procedimento.

A presença de respostas humanas conflituosas diante do processo de PVP justifica a urgência de que enfermeiros realizem uma releitura sobre a prática desse procedimento e repensem estratégias a serem implementadas na prática laboral. Estas devem ser capazes de assegurar um cuidado humanizado e sensível a esse grupo social, levando em consideração suas representações e sentimentos a fim de reduzir as respostas de enfrentamento mal adaptadas diante do procedimento.

\section{Referências}

1. Alexandrou E, Ray-Barruel G, Carr PJ, Frost SA, Inwood S, Higgins N, et al. Use of short peripheral intravenous catheters: characteristics, management, and outcomes worldwide. J Hosp Med 2018;13(5):E1-E7. https://doi.org/10.12788/jhm.3039

2. Krempser P, Arreguy-Sena C, Rodrigues BMRD, Braga LM, Parreira PMDS. Evolution of the process of peripheral venipuncture and technological resources according to nursing professionals. Cienc Cuid Saúde 2017;16(3):1-8. https://doi.org/10.4025/cienccuidsaude.v16i3.32040

3. Campos LB, Martins JR, Arreguy-Sena C, Alves MDS, Teixeira CV, Souza LCD. Experiences of hospitalized patients with the venipuncture process. EEAN. 2016; 20(3):1-9. https://doi.org/10.5935/1414-8145.20160078

4. Souza NRD, Bushatsky M, Figueiredo EGD, Melo JTDS, Freire DDA, Santos ICRV. Oncological emergency: the work of nurses in the extravasation of antineoplastic chemotherapeutic drugs. EEAN 2017;21(1):1-9. https://doi.org/10.5935/14148145.20170009

5. Braga LM, Parreira PM, Oliveira ASS, Mónico LSM, Arreguy-Sena C, Henriques MA. Phlebitis and infiltration: vascular trauma associated with the peripheral venous catheter. Rev Latinoam Enferm 2018;26:e3002. https://doi.org/10.1590/15188345.2377.3002

6. Abric JC. Prácticas sociales y representaciones. 13 ed. México, DF: Coyoacán; 2013.240p.

7. Moscovici S. Representações Sociais: investigações em psicologia Social. 11 ed. Petrópolis: Vozes; 2015. 408p.

8. Bardin L. Análise de Conteúdo. Lisboa: Edições 70; 2016. p. 280.

9. Costa LADC, Silva SF. La variación denominativa explícita en la Lexicografía en Brasil: presupuestos para la organización microestructural del Diccionario de Lexicografía Brasileña. Ibérica: Revista de la Asociación Europea de Lenguas para Fines Específicos (AELFE) 2015;(36):93-118. 
10. Brasil. Instituto Brasileiro de Geografia e Estatística (IBGE). Projeções da população: Brasil e unidades da federação: revisão 2018/IBGE, Coordenação de População e Indicadores Sociais 2 ed. Rio de Janeiro. p.58.

11. Honorato ZN, Filipini R, Alves BDCA, Azzalis LA, Junqueira VBC, Fonseca FLA. Minimização da dor na venopunção de neonatos: revisão sistemática da literatura. Enfermagem Revista 2016;19(1):117-30.

12. Queiroz CM, Arreguy-Sena C, Krempser P, Leonel M, Melo LD. Triangulação de métodos na representação social: auto punção de drogas em (ex)usuários soropositivos para HIV. RECON 2014;3(4):1229-47. https://doi.org/10.19175/recom.v0i0.435

13. Krempser P, Arreguy-Sena, Parreira PMSD, Salgueiro-Oliveira AS. Protocolo de enfermagem na prevenção de trauma vascular: bundle de cateterismo periférico em urgência. Rev Bras Enferm 2019;72(6):1589-95. https://doi.org/10.1590/0034-71672018-0457

14. Herdman $\mathrm{H} T$, Kamitsuru S. NANDA International I. Diagnósticos de Enfermagem da NANDA-I: Definições e Classificação; 2018/2020. 11 ed. Porto Alegre: Artmed; 2018. p. 1-1187.

15. Bulechek GM, Butcher HK, Dochterman J; Wagner CM. Classificação das intervenções de enfermagem (NIC) Tradução da 6. ed. Elsevier: Saraiva; 2015; p. 640.

16. Rüsch $D$, Koch $T$, Spies M, Eberhart L. Pain during venous cannulation. DtschAerzteblatt Online 2017;114(37):605-11. https://doi.org/10.3238/arztebl.2017.0605

17. Petriwskyj A, Gibson A, Webby G. Participation and power in care: Exploring the "client" in client engagement. J Aging Stud 2014;31:119-31.

https://doi.org/10.1016/.j.jaging.2014.09.007

18. Menin MSS. Representação social e estereótipo: a zona muda das representações sociais. Psic: Teor Pesq 2006;22(1):43-51. 